\title{
Clinical significance of class III B-tubulin expression and its predictive value for resistance to docetaxel-based chemotherapy in gastric cancer
}

\author{
NAOMI URANO ${ }^{1}$, YOSHIYUKI FUJIWARA ${ }^{1}$, YUICHIRO DOKI ${ }^{1}$, S.J. KIM ${ }^{2}$, YASUO MIYOSHI ${ }^{2}$, \\ SHINZABURO NOGUCHI ${ }^{2}$, HIROSHI MIYATA ${ }^{1}$, SHUJI TAKIGUCHI ${ }^{1}$, TAKUSHI YASUDA ${ }^{1}$, \\ MASAHIKO YANO ${ }^{1}$ and MORITO MONDEN ${ }^{1}$
}

Departments of ${ }^{1}$ Surgery and Clinical Oncology and ${ }^{2}$ Surgical Oncology, Graduate School of Medicine, Osaka University, 2-2 Yamadaoka (E-2), Suita, Osaka 565-0871, Japan

Received August 10, 2005; Accepted September 19, 2005

\begin{abstract}
Docetaxel, one of the most effective anticancer drugs for gastric cancer, targets $\beta$-tubulin, the major protein in mitotic spindles. Eight isotypes of B-tubulin, with tissue and organspecific expression, have been identified in mammalian cells. We examined class III B-tubulin expression in gastric cancer and assessed its relationship with sensitivity to docetaxelbased chemotherapy. A total of 115 paraffin-embedded gastric tumors were analyzed by immunohistochemistry for class III B-tubulin expression. Twenty patients with advanced gastric cancer received preoperative docetaxel-based chemotherapy. Their biopsied specimens, obtained by endoscopy before chemotherapy were examined for class III $ß$-tubulin expression. The relationship between expression and chemosensitivity was assessed. Forty-two (36.4\%) of 115 cases were confirmed to be positive for class III $\beta$-tubulin expression. There was no association between clinicopathological status and prognosis. Among the patients positive for class III B-tubulin expression, only $16.7 \%$ showed no response to chemotherapy, while $64.3 \%$ responded to the chemotherapy in the negative group. Our results suggest that class III $\beta$-tubulin is a simple and useful predictive marker for the clinical response to docetaxel-based chemotherapy in gastric cancer.
\end{abstract}

\section{Introduction}

Chemotherapy has achieved favorable results for unresectable advanced and recurrent gastric cancer $(1,2)$ and docetaxel has proved to be the cornerstone of chemotherapy regimens for

Correspondence to: Dr Yoshiyuki Fujiwara, Department of Surgery and Clinical Oncology, Graduate School of Medicine, Osaka University, 2-2 (E-2) Yamadaoka, Suita, Osaka 565-0871, Japan

E-mail: fujiwara@surg2.med.osaka-u.ac.jp

Key words: class III B-tubulin, docetaxel resistance, gastric cancer, p53 gene mutation gastric cancer (3,4; Ajani et al, Proc ASCO 22: abs. 249, 2003). Several clinical trials of docetaxel-containing combination chemotherapy have demonstrated a favorable response rate, ranging from 28 to $56 \%(3,4)$. A recent international phase III trial reported that docetaxel combined with the standard regimen of cisplatin (CDDP) and 5-fluorouracil (5-FU) showed a significantly superior response compared with the standard regimen of CDDP and 5-FU. However, more than half of the gastric cancer patients currently treated with chemotherapy do not respond to the therapy (5). Therefore, the establishment of criteria that can be used to predict chemosensitivity is important for improving the application of chemotherapy and preventing unnecessary side effects.

Docetaxel is a microtubule-disrupting agent which operates by binding to $\beta$-tubulin, a microtubule subunit (6). Docetaxel induces polymerization of tubulins and stabilizes the microtubules (7), which finally blocks the cell cycle at G2-M phase $(8,9)$. There are at least eight $\beta$-tubulin isotypes in mammalian cells (classes I, II, III, IVa, IVb, V, VI, and VII), and the composition of $ß$-tubulin isotypes varies in various human tissues (10). Class I B-tubulin is ubiquitously expressed in all human tissues and class III $\beta$-tubulin is specifically expressed in the nervous system (11). The expression of class III ß-tubulin has also been documented in non-neuronal tumors, neuroendocrine tumors (carcinoids) of the gastrointestinal tract (12) and colon adenocarcinomas (13). Furthermore, overexpression of class III ß-tubulin has been observed in several cancer cell lines such as those of non-small cell lung cancer, prostate, ovarian, and breast cancer $(10,14-16)$. Cells overexpressing class III ß-tubulin show resistance to docetaxel and paclitaxel, another microtubule-polymerizing agent (10,15-19). Moreover, a significant correlation was described between higher concentrations of class I and III B-tubulin mRNAs, as determined by quantitative RT-PCR, and resistance to docetaxel in breast cancer (20). These results suggest that expression levels of class III B-tubulin could potentially serve as a useful predictor for tumor sensitivity to docetaxel.

We have developed a simple immunohistochemical test for expression of class III B-tubulin and assessed its clinical usefulness in the prediction of chemosensitivity using specimens biopsied endoscopically before therapy. 
Table I. The primer sets of the P53 gene.

\begin{tabular}{lll}
\hline Exon & \multicolumn{1}{c}{ Forward } & \multicolumn{1}{c}{ Reverse } \\
\hline $4-1^{\text {a }}$ & 5'-TGGTCCTCTGACTGCTCTTT & 5'-GGTGTAGGAGCTGCTGGTGC \\
$4-2^{\mathrm{a}}$ & 5'-AAGACCCAGGTCCAGATGA & 5'-GAAGGGACAGAAGATGACAG \\
$4-3^{\mathrm{a}}$ & 5'-CACCAGCAGCTCCTACACCG & 5'-GGCCAGGCATTGAAGCTTCA \\
5 & 5'-CTTGTGCCCTGACTTTCAAC & 5'-CTCTCCAGCCCCAGCTGCTC \\
6 & 5'-TGATTCCTCACTGATTGCTCT & 5'-CCAGAGACCCCAGTTGCAAA \\
7 & 5'-TCTTGGGCCTGTGTTATCTC & 5'-TGCAGGGTGGCAAGTGGCTCC \\
8 & 5'-GCTTCTCTTTTCCTATCCTGA & 5'-ACCGCTTCTTGTCCTGCTTGC \\
9 & 5'-CAAGAAGCGGTGGAGGAGAC & 5'-AAGAGGTCCCAAGACTTAGT \\
\hline
\end{tabular}

${ }^{\text {a} E x o n ~} 4$ is 279 base pairs long and divided into three regions.

Several studies have demonstrated that chemo-resistance is partly due to genetic alterations in tumor tissue $(21,22)$. Perhaps the most important gene associated with chemosensitivity is $\mathrm{p} 53$, which activates genes involved in cell-cycle arrest and DNA repair after DNA damage and apoptosis. Many cytotoxic agents, such as cisplatin and 5-FU, are thought to induce p53-dependent apoptotic cell death $(23,24)$. Therefore, biopsies obtained before treatment were also screened for $\mathrm{p} 53$ gene mutation profile to assess its clinical application in predicting chemosensitivity.

\section{Materials and methods}

Materials and chemotherapy protocol. We used paraffin blocks of surgical specimens obtained from 115 patients with gastric cancer and 20 specimens endoscopically biopsied before chemotherapy at Osaka University Hospital. Twenty patients with advanced gastric cancer received combination chemotherapy of docetaxel, 5-FU, and CDDP. The treatment cycle consisted of docetaxel $\left(60 \mathrm{mg} / \mathrm{m}^{2}\right.$ on day 1$), 5 \mathrm{FU}\left(350 \mathrm{mg} / \mathrm{m}^{2}\right.$ over $24 \mathrm{~h}$ on day $1-5)$ and CDDP $\left(10 \mathrm{mg} / \mathrm{m}^{2}\right.$ on day $\left.1-5\right)$ and was repeated twice every 3 weeks and the clinical response to chemotherapy was evaluated. The study protocol was approved by the Institutional Review Board of Osaka University Medical School (Osaka, Japan), and written informed consent was obtained from each patient.

Evaluation of clinical response. The clinical response to chemotherapy was assessed in accordance with WHO criteria as follows: i) complete response (CR), disappearance of all known disease; ii) partial response (PR), $\leq 50 \%$ decrease in entire tumor burden; iii) no change (NC), $<50 \%$ decrease or $<25 \%$ increase in entire tumor burden; and 4) progressive disease (PD), $\geq 25 \%$ increase in the entire tumor burden or appearance of new lesions. The entire tumor burden was measured by computed tomography scan and endoscopy before and after chemotherapy. Patients with CR and PR were defined as responders, and patients with $\mathrm{NC}$ and $\mathrm{PD}$ were defined as non-responders.

Immunohistochemistry. Formalin-fixed paraffin-embedded tissue was cut in $4-\mu \mathrm{m}$ thick sections. Immunohistochemical staining for class III ß-tubulin was performed with the avidinbiotin-peroxidase complex $(\mathrm{ABC})$ method using the Histofine SAB-PO Kit (Nichirei, Tokyo). The primary antibody for class III was purchased as monoclonal IgG (clone TU-20) (1:200, Chemicon International, CA). After deparaffinization and rehydration, sections were immersed in antigen retrieval buffer at $95^{\circ} \mathrm{C}$ for $45 \mathrm{~min}$. Subsequent steps were performed according to the instructions provided by the manufacturer. Neuroblastoma tissue resected during pediatric surgery was used as a positive control. The expression of class III B-tubulin was defined as positive if cytoplasmic staining was observed in $>10 \%$ of cancer cells.

DNA extraction. Pre-treatment biopsy specimens from 17 patients who received neoadjuvant chemotherapy were analyzed. Genomic DNA was extracted from formalin-fixed paraffin-embedded tissue using Sepagene (Takara, Sankou junyaku, Japan) according to the instructions provided by the manufacturer.

Polymerase chain reaction. The primer sets were designed to amplify the coding region of the p53 gene, including exons (Table I). The PCR reaction mixture contained $100 \mathrm{ng}$ of template DNA, 2 pmol of each primer set, $0.5 \mathrm{U}$ of Taq polymerase (AmpliTaq Gold, Applied Biosystems, Roche), and $2.5 \mathrm{mM} \mathrm{MgCl}_{2}$. The PCR cycling condition was set up as follows: an initial denaturing step at $95^{\circ} \mathrm{C}$ for $10 \mathrm{~min}$; 40 cycles of $95^{\circ} \mathrm{C}$ for $30 \mathrm{sec}, 50^{\circ} \mathrm{C}-58^{\circ} \mathrm{C}$ for $30 \mathrm{sec}$ and $72^{\circ} \mathrm{C}$ for $30 \mathrm{sec}$; and a final period of extension at $72^{\circ} \mathrm{C}$ for $5 \mathrm{~min}$. For amplification of the whole region of exon 4 , the extension time was extended by $2 \mathrm{~min}$.

Single-strand conformation polymorphism (SSCP) analysis. SSCP analysis was performed using 5\% non-denaturing polyacrylamide gels (acrylamide: N,N-bisacrylamide 99:1) containing $10 \%$ glycerol. After electrophoresis $(4.5 \mathrm{~h}, 850 \mathrm{~V})$, the gels were stained with SYBR-Green II (Takara, Otsu, Japan) and scanned with a fluorescence image analyzer (FMBio II Multi-View, Takara).

Sequence analysis. Bands shifting in SSCP were cut out and amplified by PCR. PCR products were purified and sequenced 

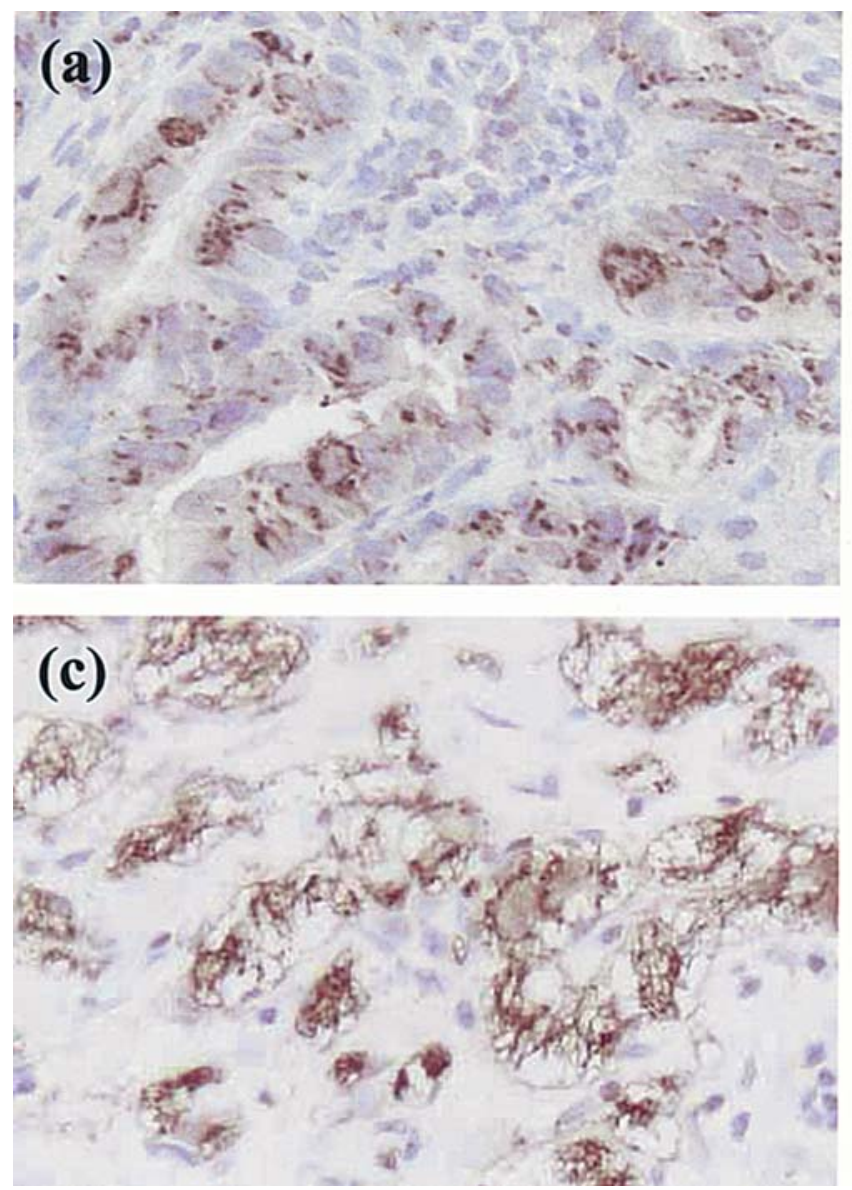

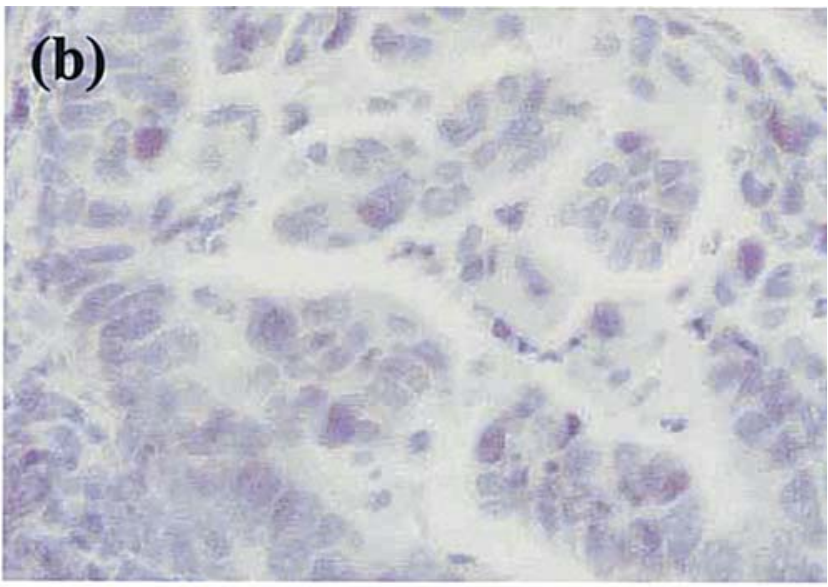

Figure 1. Immunohistochemical analysis of class III $\beta$-tubulin. The expression of class III was defined as positive if cytoplasmic staining was observed in $>10 \%$ of cancer cells. (a) Representative positive case: the majority of cancer cells showed positive staining in the cytoplasm (x400). (b) Representative negative case: no immunoreactivity was evident (x400). (c) Neuroblastoma tissue sample was used as a positive control (x400). using the Direct Sequence kit (Big Dye Terminator version 3, Cycle sequencing ready reaction kit, ABI PRISM).

Statistical analysis. The significance of associations between each clinicopathological variable and expression of class III was determined using $\chi^{2}$ test or Spearman's test. Survival curves were drawn according to the Kaplan-Meier method and evaluated using the log-rank test. Correlations between chemotherapy response, class III expression, and p53 mutation status were determined by Spearman's test. $\mathrm{P}$ values $<0.05$ were considered statistically significant.

\section{Results}

Expression of class III $\beta$-tubulin in gastric cancer. Expression of class III B-tubulin protein was detected in 42 (36.5\%) of 115 gastric cancer cases. Fig. 1 displays immunohistochemical staining of a representative class III $B$-tubulin-positive specimen, showing cytoplasmic staining of cancer cells. There was no association between the expression of class III B-tubulin and any clinicopathological factors, such as histological type, depth of invasion in the gastric wall, lymph node metastasis and clinical stage (Table II). In addition, there was no association between increased expression of class III ß-tubulin and patient survival (Fig. 2).

Clinical outcome of patients with docetaxel-based chemotherapy. The clinical details of 20 patients who received neoadjuvant chemotherapy including docetaxel and their
Table II. Class III expression and clinicopathological status.

\begin{tabular}{|c|c|c|c|c|}
\hline \multirow{2}{*}{$\begin{array}{l}\text { Clinicopatho- } \\
\text { logical status }\end{array}$} & \multirow[b]{2}{*}{ Total } & \multicolumn{2}{|c|}{ Class III } & \multirow{2}{*}{ P-value } \\
\hline & & Negative & Positive & \\
\hline Numbers & 115 & 73 & 42 & \\
\hline \multicolumn{5}{|l|}{ Histology } \\
\hline Differentiated & 63 & 37 & 26 & \multirow{2}{*}{0.2465} \\
\hline Undifferentiated & 52 & 36 & 16 & \\
\hline \multicolumn{5}{|l|}{ T stage } \\
\hline 1 & 60 & 33 & 27 & \multirow{2}{*}{0.1211} \\
\hline$\geq 2$ & 55 & 40 & 15 & \\
\hline \multicolumn{5}{|l|}{ N stage } \\
\hline- & 75 & 45 & 32 & \multirow{2}{*}{0.1119} \\
\hline+ & 38 & 28 & 10 & \\
\hline \multicolumn{5}{|l|}{ Disease stage } \\
\hline I & 56 & 31 & 25 & \multirow{2}{*}{0.1164} \\
\hline$\geq \mathrm{II}$ & 59 & 42 & 17 & \\
\hline \multicolumn{5}{|l|}{ Age } \\
\hline$<50$ & 18 & 11 & 7 & \multirow{3}{*}{0.5282} \\
\hline $50-70$ & 68 & 42 & 26 & \\
\hline$>70$ & 29 & 20 & 9 & \\
\hline \multicolumn{5}{|l|}{ Gender } \\
\hline M & 88 & 58 & 30 & \multirow[t]{2}{*}{0.5282} \\
\hline $\mathrm{F}$ & 27 & 15 & 12 & \\
\hline
\end{tabular}




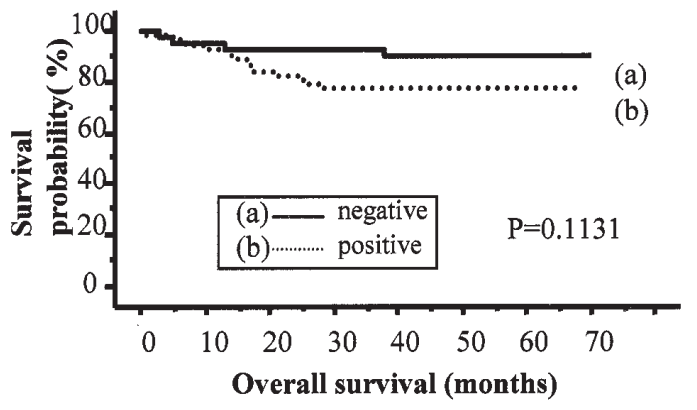

Figure 2. Association between class III expression and patient survival in gastric cancer. There was no significant association between increased expression of class III $\beta$-tubulin and survival in gastric cancer $(\mathrm{P}=0.1131)$. (a) Negative cases. (b) Positive cases.

responses to chemotherapy, are presented in Table III. PR, NC, and PD were noted in 10, 7, and 3 cases, respectively; with a $50 \%$ response rate to chemotherapy (10 out of 20 cases).

Class III $\beta$-tubulin expression and response to chemotherapy. The clinical response to chemotherapy and expression of class III protein are presented in Table IV. Case 12, with a
Table IV. Class III expression and response to chemotherapy.

\begin{tabular}{lccc}
\hline & \multicolumn{2}{c}{ Response to chemotherapy } & \\
\cline { 2 - 3 } & Responders & Non-responders & Response rate (\%) \\
\hline Class III & & & \\
Positive & 1 & 5 & 16.7 \\
Negative & 9 & 5 & 64.3 \\
\hline
\end{tabular}

pre-treatment biopsy specimen negative for class III $\beta$-tubulin, showed a good response to docetaxel-based chemotherapy (Fig. 3). Histopathological examination showed no residual tumor cells in the primary tumor region and lymph nodes. In contrast, case 17 , with a pre-treatment biopsy specimen positive for class III $\beta$-tubulin, showed progressive disease despite docetaxel-based chemotherapy (Fig. 4). The correlation between class III B-tubulin expression and clinical outcome of chemotherapy are shown in Fig. 5 and Table III. A total of $83.3 \%$ (5 out of 6 ) of cases positive for class III expression showed no response to the therapy while $35.7 \%$ (5 out of 14 )

Table III. Clinical features of patients with gastric cancer who received docetaxel-based chemotherapy.

\begin{tabular}{|c|c|c|c|c|c|c|c|c|c|c|c|c|}
\hline Case & Age & Gender & Histology & $\mathrm{T}$ & $\mathrm{N}$ & M & Stage & ßIII & p53 status & $\begin{array}{l}\text { Position } \\
\text { (codon) }\end{array}$ & Variation & Response \\
\hline 1 & 34 & $\mathrm{~F}$ & sig & 3 & 2 & 0 & IIIB & - & MT & EX7(244) & Arg/Met & $\mathrm{NC}$ \\
\hline 2 & 39 & M & sig & 3 & 1 & 0 & IIIA & - & WT & & & PR \\
\hline 3 & 62 & $\mathrm{~F}$ & sig & 3 & 2 & 0 & IIIB & - & WT & & & PR \\
\hline 4 & 70 & M & por & 3 & 1 & 0 & IIIA & - & WT & & & PR \\
\hline 5 & 49 & M & tub2 & 3 & 1 & 1 & IV & - & MT & EX4(111) & Leu/Met & $\mathrm{NC}$ \\
\hline 6 & 73 & M & por & 2 & 1 & 1 & IV & + & WT & & & $\mathrm{NC}$ \\
\hline 7 & 57 & $\mathrm{~F}$ & por & 2 & 0 & 1 & IV & + & MT & EX8(280) & Ile/Lys & PD \\
\hline 8 & 31 & $\mathrm{M}$ & por & 2 & $\mathrm{M}$ & 1 & IV & + & WT & & & $\mathrm{NC}$ \\
\hline 9 & 70 & M & tub2 & 3 & 1 & 0 & IV & - & MT & EX4(121) & Ser/Cys & PD \\
\hline 10 & 65 & M & por & 3 & 1 & 0 & IIIA & - & WT & & & $\mathrm{NC}$ \\
\hline 11 & 61 & $\mathrm{M}$ & tub2 & 3 & 1 & 0 & IV & - & MT & EX4(111) & Leu/Met & $\mathrm{NC}$ \\
\hline 12 & 68 & M & por & 3 & 1 & 0 & IIIA & - & WT & & & PR \\
\hline 13 & 70 & $\mathrm{M}$ & tub2 & 3 & 1 & 0 & IIIA & - & MT & EX5(154) & Gly/Asp & PR \\
\hline 14 & 54 & M & tub1 & 3 & 2 & 0 & IIIB & + & WT & & & PR \\
\hline 15 & 59 & M & tub2 & 2 & 2 & 1 & IV & - & MT & EX7(244) & Arg/Met & PR \\
\hline 16 & 54 & M & tub1 & 3 & 2 & 1 & IV & - & WT & & & PR \\
\hline 17 & 34 & $\mathrm{M}$ & tub1 & 3 & 0 & 1 & IV & + & MT & EX7(244) & Arg/Met & PD \\
\hline 18 & 53 & $\mathrm{~F}$ & por & 3 & 2 & 0 & IIIB & + & a & & & $\mathrm{NC}$ \\
\hline 19 & 72 & M & pap & 3 & 2 & 0 & IIIB & - & a & & & PR \\
\hline 20 & 29 & $\mathrm{M}$ & por & 3 & $\mathrm{M}$ & 1 & IV & - & a & & & PR \\
\hline
\end{tabular}

Ten of 20 patients (50\%) responded to chemotherapy. sig, signet-ring cell adenocarcinoma; poor, poorly differentiated adenocarcinoma; tub2, moderately differentiated adenocarcinoma; tub1, highly differentiated adenocarcinoma; BIII(-/+), negative/positive; p53 status (WT/MT), wild-type/mutation; PR, partial response; NC, no change; PD, progressive disease. a DNA could not be extracted from these samples. 
b

\section{a}

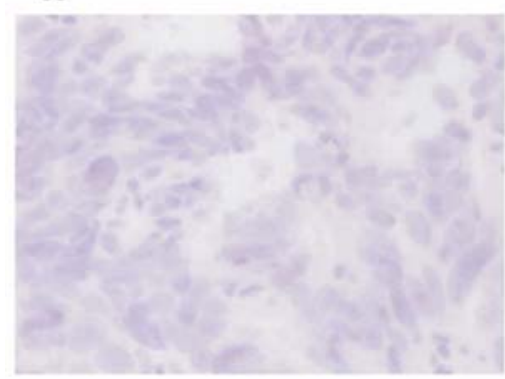

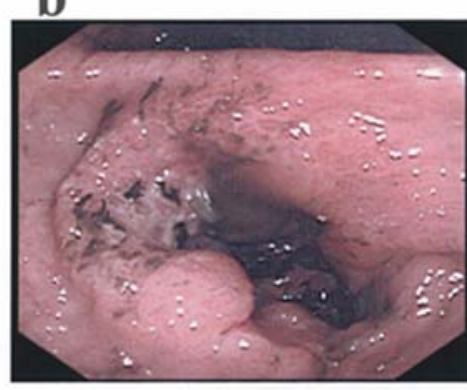

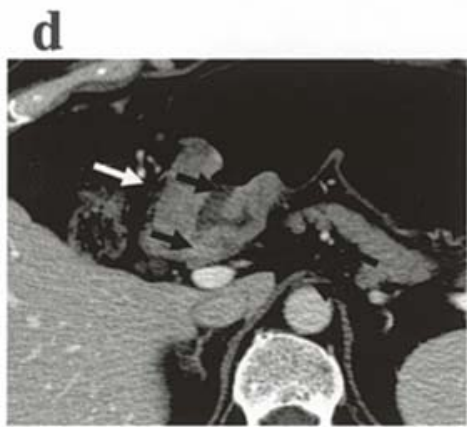

c

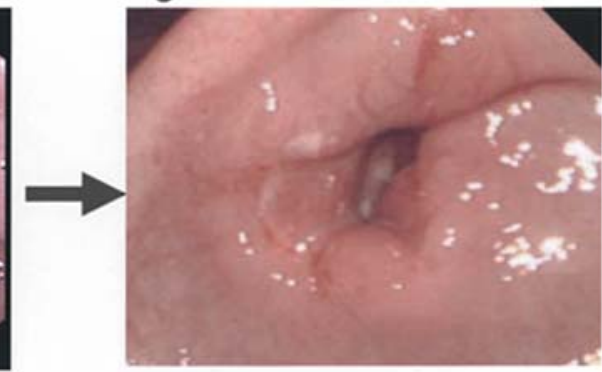

e

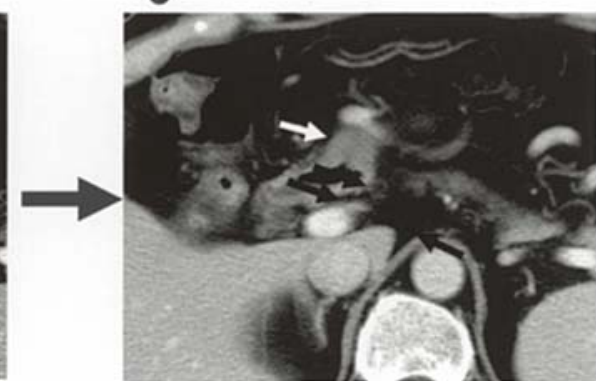

Figure 3. A representative class III negative case with a good response to docetaxel-based chemotherapy. Case 12 , class III 3 -tubulin-negative with a good response to docetaxel-based chemotherapy. (a) Class III expression in pre-treatment biopsy taken from a primary lesion. Cancer cells did not stain completely. (b) Endoscopic view of the primary lesion by before chemotherapy and (c) after chemotherapy. (d) Computerized tomography before chemotherapy and (e) after chemotherapy.

a

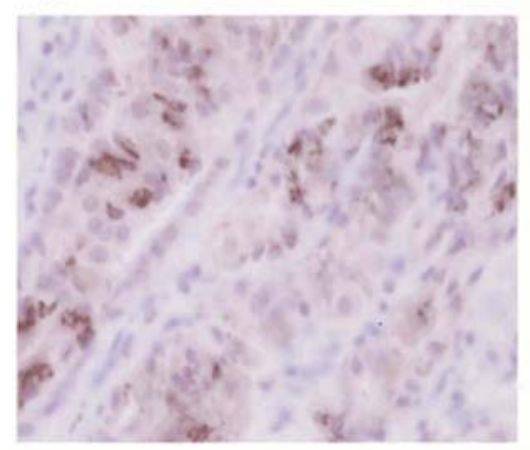

b

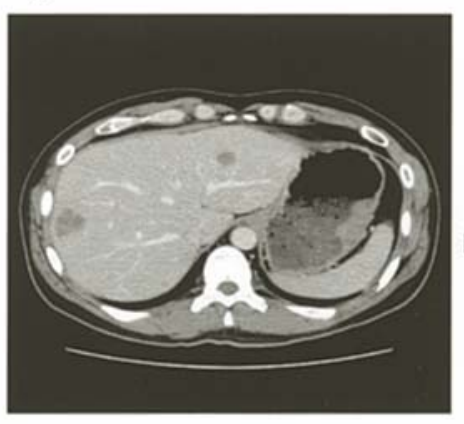

d

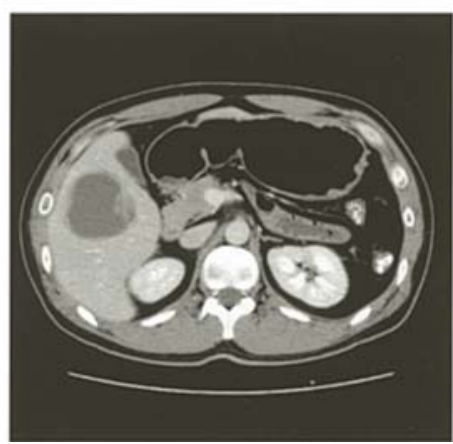

c

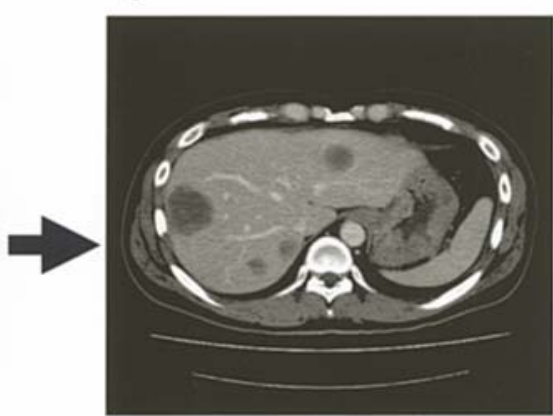

e

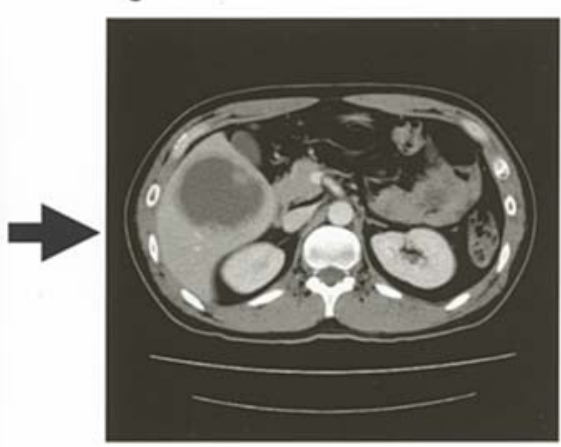

Figure 4. A representative case of high class III expression with no response to docetaxel-based chemotherapy. Case 17 , class III 3 -tubulin-positive by immunohistochemical examination, showed progressive disease. (a) Positive cytoplasmic staining in $>50 \%$ of cancer cells in the pre-treatment biopsy. (b and d) Images of liver metastases by computerized tomography before chemotherapy; (c and e) Images of liver metastases by computerized tomography after chemotherapy.

of cases negative for class III $\beta$-tubulin were non-responders (Table IV). These results suggest that expression of class III
B-tubulin is a potentially useful marker of resistance to docetaxel-based chemotherapy in gastric cancer. 


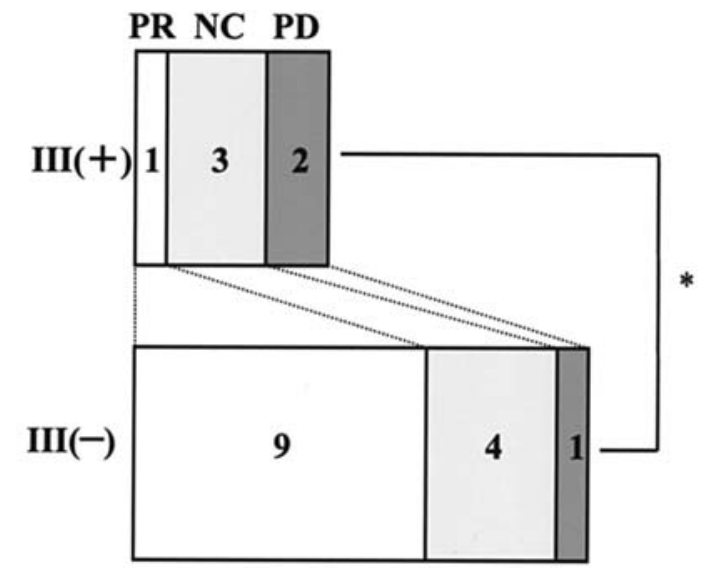

Figure 5. Correlation between class III ß-tubulin expression and clinical response to chemotherapy. Patients with gastric cancer expressing class III ß-tubulin (III+) were more likely to develop resistance to docetaxel-based chemotherapy than patients negative for the expression (III-) $\left({ }^{*} \mathrm{P}=0.0418\right)$.

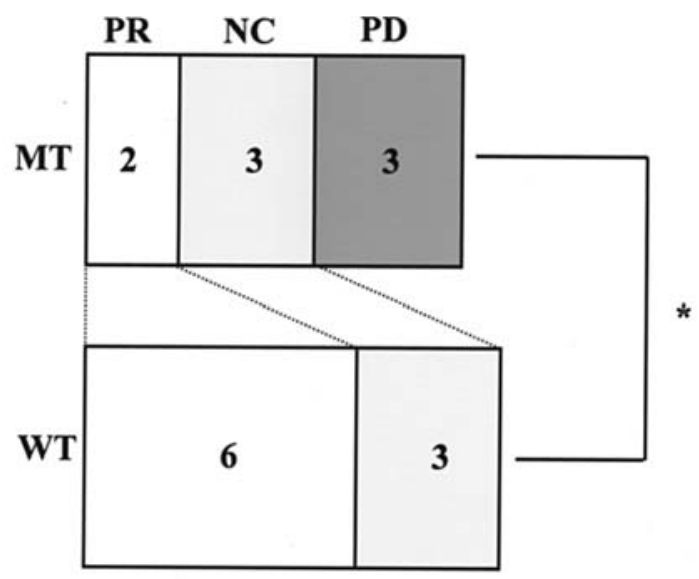

Figure 6. Correlation between mutated p53 gene and clinical response to chemotherapy. Patients with gastric cancer positive for mutated p53 (MT) were generally more likely to develop resistance to combination chemotherapy than those with wild-type p53 (WT). However, the difference was not significant $\left({ }^{*} \mathrm{P}=0.0606\right)$.

Table V. p53 status and response to chemotherapy.

Response to chemotherapy

Responders Non-responders Response rate (\%)

P53 status

\begin{tabular}{llll} 
Mutant & 2 & 6 & 25.0 \\
Wild-type & 6 & 3 & 66.7 \\
\hline
\end{tabular}

p53 gene mutation and chemosensitivity. Fig. 6 and Table V show the association between the p53 mutation status and the clinical response to neoadjuvant chemotherapy. The response rate was higher in patients with wild-type p53 (67\%, 6 out of 9) than in patients with mutated p53 (25\%, 2 out of 8$)$. However, there was no statistically significant difference between the mutation status of p53 and chemosensitivity.

\section{Discussion}

The mechanisms by which tumor cells acquire resistance to taxanes, such as docetaxel and paclitaxel, are not fully understood. The multidrug transporter, P-glycoprotein, has been implicated in the acquisition of chemotherapy resistance in prostate cancer (25) and pancreatic adenocarcinoma (26). However, the association between P-glycoprotein and response to docetaxel has not been supported by data from a study of human breast cancer (27). Another proposed mechanism is the association between paclitaxel resistance and $\beta$-tubulin somatic mutations in non-small cell lung cancer (28). However, somatic mutations in the class I B-tubulin gene were confirmed to be very rare in non-small cell lung cancer, ovarian cancer (29), and breast cancer (30). Furthermore, we also showed that, in gastric cancer tissue, there were no somatic mutations in the class I B-tubulin gene (31). These results indicated that somatic mutations in $\beta$-tubulin, which may induce resistance to taxanes, were very rare in humans and thus not suitable for use as predictive markers for resistance to taxane chemotherapy.

Eight distinct isotypes of $\beta$-tubulin, with tissue-specific expression, have been identified in mammalian cells. Several studies have shown that overexpression of specific B-tubulin isotypes, including class IIIß-tubulin, are associated with resistance to paclitaxel in various human cancers $(10,13-19)$. Furthermore, it has been demonstrated that the use of antisense oligonucleotides to class III ß-tubulin restores paclitaxel sensitivity in previously paclitaxel-resistant lung cancer cell lines (16). These in vitro experiments indicated that the expression of tubulin isotype in tumors could be a predictive marker for chemosensitivity. Furthermore, high expression levels of class I and III ß-tubulin mRNAs in breast cancer tissue also correlate significantly with resistance to docetaxel (20).

In the present study, we focused on the expression of class III B-tubulin in gastric cancer and showed that isotype expression detected by simple immunohistochemical analysis could be a useful predictive marker for resistance to docetaxelbased chemotherapy. The mechanism responsible for resistance to chemotherapy, which is associated with class III B-tubulin expression, is the subject of speculation. Panda et al (32) demonstrated that microtubules assembled from the purified $\beta$-tubulin and class III $\beta$-tubulin $(\alpha / \beta I I I)$ had more dynamic properties in growing and shortening of microtubules than those consisting of $\alpha / \beta$ II or $\alpha /$ IIV tubulins. Furthermore, Khan and Luduena (33) also demonstrated that BII phosphorylation might play a role in regulation of the microtubule's dynamics, which influences the instability of microtubules. The dynamic behavior and instability of microtubules is thought to play a major role in taxane chemoresistance.

The chemotherapy regimen used in our study included 5-FU and CDDP, both well known as DNA damaging agents $(34,35)$. Analysis of the mutated p53 gene in biopsied specimens and the associations with chemosensitivity showed a tendency for tumors with mutated p53 to resist chemotherapy. However, this relationship was not statistically significant.

In the present study, we demonstrated that overexpression of class III B-tubulin isotype was associated with resistance to docetaxel in gastric cancer. Immunohistochemical analysis 
of pre-treatment biopsies for class III ß-tubulin may contribute to the improvement of gastric cancer therapy by avoiding the selection of ineffective chemotherapy regimens.

\section{References}

1. Pyrhonen S, Kuitunen T, Nyandoto P and Kouri M: Randomised comparison of fluorouracil, epidoxorubicin and methotrexate (FEMTX) plus supportive care with supportive care alone in patients with non-resectable gastric cancer. $\mathrm{Br} \mathrm{J}$ Cancer 71: 587-591, 1995.

2. Glimelius B, Ekstrom K, Hoffman K, et al: Randomized comparison between chemotherapy plus best supportive care with best supportive care in advanced gastric cancer. Ann Oncol 8: 163-168, 1997.

3. Roth AD, Maibach R, Martinelli G, et al: Docetaxel (Taxotere)cisplatin(TC): an effective drug combination in gastric carcinoma. Swiss Group for Clinical Cancer Research (SAKK), and the European Institute of Oncology (EIO). Ann Oncol 11: 301-306, 2000.

4. Roth AD and Ajani J: Docetaxel-based chemotherapy in the treatment of gastric cancer. Ann Oncol 14: 241-244, 2003.

5. Atsushi O: Current status and future prospects of chemotherapy for metastatic gastric cancer: a review. Gastric Cancer 8: 95-102, 2005.

6. Parness $\mathrm{J}$ and Horwitz SB: Taxol binds to polymerized tubulin in vitro. J Cell Biol 91: 479-487, 1981.

7. Horwitz SB, Cohen D and Rao S: Taxol: mechanism of action and resistance. Monogr J Natl Cancer Inst 5: 55-61, 1993.

8. Milross CG, Mason KA, Hunter NR, Chung YK, Peters LJ and Milas L: Relationship of mitotic arrest and apoptosis to antitumor effect of paclitaxel. J Natl Cancer Inst 88: 1308-1314, 1996.

9. Long BH and Fairchild C.R: Paclitaxel inhibits progression of mitotic cell to $\mathrm{G}$ phase by interference with spindle formation without affecting other microtubule functions during anaphase and telophase. Cancer Res 54: 4355-4361, 1994.

10. Banerjee A: Increased levels of tyrosinated alpha-, beta (III)and beta (IV)-tubulin isotypes in paclitaxel-resistant MCF-7 breast cancer cells. Biochem Biophys Res Commun 293: 598-601, 2002.

11. Lewis A, Lee G and Cowan J: Five mouse tubulin isotypes and regulated expression during development. J Cell Biol 101: 852-861, 1985.

12. Jirasek T, Mandys V and Viklicky V: Expression of class III $\beta$-tubulin in neuroendocrine tumors of gastrointestinal tract. Folia Histochem Cytobiol 40: 305-310, 2002.

13. Carles G, Braguer D, Dumontet C, et al: Differentiation of human colon cancer cells changes the expression of $\beta$-tubulin isotypes and MAPs. Br J Cancer 80: 1162-1168, 1999.

14. Carles D, Sylvic I, Pierre-JS, et al: Expression of class III ßtubulin in non-small cell lung cancer is correlated with resistance to taxane chemotherapy. Bull Cancer 92: 25-30, 2005.

15. Kavallaris M, Kuo DYS, Burkhart CA, et al: Taxol-resistant epithelial ovarian tumors are associated with altered expression of specific B-tubulin isotypes. J Clin Invest 100: 1282-1293, 1997.

16. Kavallaris M, Burkhart CA and Horwitz SB: Antisense oligonucleotides to class III B-tubulin sensitize drug-resistant cells to Taxol. Br J Cancer 80: 1020-1025, 1999.
17. Ranganathan S, Dexter DW, Benetatos CA, Chapman AE, Tew KD and Hudes GR: Increase of III- and IVa-tubulin isotypes in human prostate carcinoma cells as a result of estramustine resistance. Cancer Res 56: 2584-2589, 1996.

18. Ranganathan S, Dexter DW, Benetatos CA and Hudes GR: Cloning and sequencing of human III-tubulin cDNA: induction of III isotype in human prostate carcinoma cells by acute exposure to antimicrotubule agents. Biochim Biophys Acta 1395: 237-245, 1998

19. Ranganathan S, Benetatos CA, Colarusso PJ, Dexter DW and Hudes GR: Altered -tubulin isotype expression in paclitaxelresistant human prostate carcinoma cells. Br J Cancer 77: 562-566, 1998.

20. Hasegawa S, Miyoshi Y, Egawa C, et al: Prediction of response to docetaxel by quantitative analysis of class I and III $\beta$-tubulin isotype mRNA expression in human breast cancers 9: 2992-2997, 2003.

21. Lowe SW, Bodis S, McClatchey A, et al: p53 status and the efficacy of cancer therapy in vivo. Science 266: 807-810, 1994.

22. Ricky J, Astrid R and Scott L: Apoptosis: a link between cancer genetics and chemotherapy. Cell 108: 153-164, 2002.

23. Fouret P, Temam S, Charlotte F and Lacau J: Tumor stage, node stage, p53 gene status and bcl-2 protein expression as predictors of tumor response to platin-fluorouracil chemotherapy in patients with squamous-cell carcinoma of the head and neck. $\mathrm{Br}$ J Cancer 87: 1390-1395, 2002.

24. Alnuld C, Helene B, Isabelle de W, et al: P53 alterations predict tumor response to neoadjuvant chemotherapy in head and neck squamous cell carcinoma: A prospective series. J Clin Oncol 18: 1465-1473, 2000.

25. Makatovskiy AN, Siryaporn E, Hixson DC and Akerley W: Survival of docetaxel-resistant prostate cancer cells in vitro depends on phenotype alterations and continuity of drug exposure. Cell Mol Life Sci 59: 1198-1211, 2002.

26. Bin L, Edger DS, Takeshi I, Hubert EA and John MH: Mechanisms of taxotere-related drug resistance in pancreatic carcinoma. J Surg Res 99: 179-186, 2001.

27. Egawa C, Miyoshi Y, Takamura Y, Taguchi T, Tamaki Y and Noguchi S: Decreased expression of BRCA2 mRNA predicts favorable response to docetaxel in breast cancer. Int $\mathrm{J}$ Cancer 95: 255-259, 2001.

28. Achiwa H, Sato S, Shimizu S, et al: Analysis of ß-tubulin gene alteration in human lung cancer cell lines. Cancer Lett 1: 211-216, 2003.

29. Sale S, Sung R, Shen P, et al: Conservation of the class I Btubulin gene in human populations and lack of mutations in lung cancers and paclitaxel-resistant ovarian cancers. Mol Cancer Ther 1: 215-225, 2002.

30. Maeno K, Ito K, Hama Y, et al: Mutation of the class I B-tubulin gene dose not predict response to paclitaxel for breast cancer. Cancer Lett 30: 89-97, 2003.

31. Urano N, Fujiwara Y, Hasegawa S, et al: Absence of betatubulin gene mutation in gastric carcinoma. Gastric Cancer 6: 108-112, 2003.

32. Dulal P, Herbert PM, Asok B, Richard FL and Leslie W: Microtubules dynamics in vitro are regulated by the tubulin isotype composition. Proc Natl Acad Sci USA 91: 11358-11362, 1994.

33. Khan IA and Luduena RF: Phosphorylation of BIII-tubulin. Biochemistry 35: 3704-3711, 1996.

34. Parker WB and Cheng YC: Metabolism and mechanism of action of 5-fluorouracil. Pharmacol Ther 48: 381-395, 1990.

35. Deborah BZ and Stephen JL: Cisplatin and DNA repair in cancer chemotherapy. TIBS 20: 435-439, 1995. 